\title{
Impact of a health educational guidelines on the knowledge, self-management practice and self-efficacy of patients with type- 2 diabetes
}

\author{
Nadia Mohamed Taha ${ }^{* 1}$, Howida kameel Zaton ${ }^{1}$, Nahla Ahmed Abd Elaziz ${ }^{2}$ \\ ${ }^{1}$ Medical-Surgical Nursing, Faculty of Nursing, Zagazig University, Egypt \\ ${ }^{2}$ Community Health Nursing, Faculty of Nursing, Ain Shams University, Egypt
}

Received: January 7, 2016

DOI: $10.5430 /$ jnep.v6n9p46

\author{
Accepted: March 23, 2016 \\ Online Published: April 25, 2016 \\ URL: http://dx.doi.org/10.5430/jnep.v6n9p46
}

\begin{abstract}
Background: Diabetes is a common costly condition associated with significant morbidity and mortality. The process of teaching individuals to manage their diabetes had been considered an important part of the clinical management. The goals of self-management education are to optimize metabolic control, prevent acute and chronic complications, and optimize quality of life; Aim: To evaluate the impact of a health education intervention guidelines for T2DM on Patients' knowledge, self-efficacy, and self-management practices.

Methods: Design: quasi-experimental uncontrolled design on 50 patients evaluated at pre-intervention, post-intervention, and 6-month follow-up. Setting: The study was carried out in the outpatient clinics of Endocrinology and Metabolism at Zagazig University Hospital. Tools: three tools were used, 1st tool was an interview questionnaire to assess socio-demographic data and patients' knowledge, self-efficacy scale and patients' self-reported self-management behaviors concerning self-care practices.

Results: There were statistically significant improvements in patients' knowledge $(p<.001)$, self-efficacy $(p<.001)$, and selfmanagement $(p<.001)$, which continued through follow-up. Multivariate analysis showed that the knowledge and self-efficacy scores positively predicted the scores of self-management.

Conclusions: The study demonstrates the effectiveness of health educational intervention guidelines in improving T2DM patients' self-management behaviors and self-care practices through provision of sound information and fostering their self-efficacy. The slight decline at the follow-up phase indicates the need for periodic booster doses of the intervention. Therefore, the study recommends generalization of such educational guidelines in all health care settings providing services to T2DM patients. Such guidelines should particularly address the patients with low educational attainments, long history of T2DM, and those residing in rural areas. More research is needed to investigate the long-term effect of such educational interventions.
\end{abstract}

Key Words: Type 2 diabetes, Self-efficacy, Self-management behaviors and self-care

\section{INTRODUCTION}

Diabetes mellitus (DM) is a chronic illness with high morbidity and mortality, with high public health burden. According to a recent report, approximately 180 million people have
DM worldwide, and the figure is estimated to double by the year 2030. ${ }^{[1]}$ However, and a good glycemic control is able to prevent or control its complications. ${ }^{[2]}$ This requires changes in patient's daily routine, with many self-care activi-

\footnotetext{
*Correspondence: Nadia Mohamed Taha; Email: dr_nadomohamed@yahoo.com; Address: Medical-Surgical Nursing, Faculty of Nursing, Zagazig University, Egypt.
} 
ties concerning medications, glucose testing, nutrition, and exercise. These patients need guidance to be able to pursue the life-long management of their illness. Therefore, the DM patients' education should be concerned with encouraging self-dependence and confidence among them to enable them to carry out their self-care tasks. ${ }^{[3,4]}$

Self-management is a set of daily behaviors to be followed by patients to deal with their diabetes. ${ }^{[5]}$ It is a complex process translating the required knowledge, skills and capabilities into effective patient self-management behaviors. ${ }^{[6]}$ Its main objectives are to persuade the patient to make informed decisions and to cooperate with the caregivers to enhance clinical outcomes. Determining behavioral objectives is a fundamental strategy in this process, ${ }^{[7]}$ and it should give emphasis to patient-centered care based on analysis of the needs and capabilities of the patients with respect to their experience and knowledge. ${ }^{[8]}$ There is still a need for a culture-sensitive model for T2DM self-management. ${ }^{[6]}$

Self-efficacy is an important factor influencing diabetes selfmanagement behaviors, and is a key tenet in the Social Cognitive Theory. ${ }^{[9]}$ It is a strong predictor of perceived selfcare ${ }^{[10]}$ since the perception of own ability to surmount the obstacles in a certain matter influences further attempts to engage in different behavioral challenges concerning this matter. ${ }^{[11]}$ It also reflects one's ability to adopt behavioral changes for better self-care abilities. ${ }^{[12]}$ Moreover, the level of self-efficacy influences patients' persistence. ${ }^{[13]}$ Hence, the measurement of self-efficacy can help in the prediction the intention to change and to select proper self-care interventions. ${ }^{[14]}$ In DM, self-efficacy refers to the judgment of patient's capacity to set and follow diabetes activities, ${ }^{[15]}$ with emphasis on diet, exercise, medication, and blood glucose checks. ${ }^{[16]}$ The self-efficacy framework related to DM has been applied in various education programs. ${ }^{[17]}$ These studies demonstrated that self-efficacy correlated with compliance to physical activity, ${ }^{[18]}$ and diet regimen ${ }^{[19]}$ and to be associated with more frequent self-monitoring of blood glucose $^{[20]}$ and glycemic control. ${ }^{[21]}$ Conversely, low selfefficacy was associated with worse diabetes control. ${ }^{[22]} \mathrm{Nev}-$ ertheless, although there is a consensus that self-efficacy is essential for motivation to patients in the treatment of T2DM, it is often assessed as a general measure, which may overlook its predictive usefulness. ${ }^{[14,23]}$

\subsection{Significance and aim of the study}

Diabetes mellitus is a chronic illness, rising tide of type II diabetes and its associated complications in Egypt and requiring a lifetime self-management behavior. Because diet, physical exercise, and physical and emotional stress can affect diabetic control, patients must learn to balance these

Published by Sciedu Press factors to avoid fluctuations in blood glucose levels. They must be knowledgeable about nutrition, exercise, preventive strategies, and medication adjustment. Given the increasing incidence of DM, its chronic nature with no cure, and the associated potential complications, this study was aimed at evaluating the impact of health educational guidelines for T2DM on Patients' knowledge, self-efficacy, and selfmanagement practices. The research hypotheses are that the implementation of the health educational guidelines will lead to statistically significant improvements T2DM Patients' knowledge, self-efficacy, and self-management practice.

\subsection{Theoretical framework}

Bandura's Social Cognitive Theory emphasizes how behavioral, personal (cognitive, affective, and biological events), and environmental factors interact to determine motivation and behavior. Accordingly, human functioning is the result of the interaction among all three of these factors. ${ }^{[24]} \mathrm{Hu}-$ man functioning may be primarily influenced by personal (self-efficacy), behavioral (social recognition), and environmental (sense of cohesion in work area) influences. ${ }^{[25]}$ The self-efficacy theory is based on the assumption that a person who is given the flexibility to try a task under various conditions builds a body of knowledge that increases both his/her natural ability to perform the task and the self-efficacy to believe in own ability to do it. ${ }^{[26]}$

\section{SUBJECTS AND METHODS}

\subsection{Study design and setting}

The setting was in the outpatient clinics of Endocrinology and Metabolism at Zagazig University Hospital using a quasiexperimental uncontrolled design. Patients were evaluated at three time intervals: before, post, and 6 months after intervention.

\subsection{Participants}

A convenience sample of 50 patients with T2DM having T2DM for at least one year, taking diabetes care at the study setting, and able to read and write in order to pursue the guidelines. The sample size was calculated to demonstrate a doubling (design effect 2) of the knowledge, self-efficacy, and self-management rates after the intervention, at $95 \%$ level of confidence and $80 \%$, and accounting for a dropout rate of 5\%. The patient how drop out at any phase from the study was excluded.

\subsection{Data collection tool}

The researchers used three tools, 1 st tool was an interview questionnaire for data collection, adapted by the researchers based on literature. The 1st part covered patients' personal data as age, sex, educational status, residence, occupation, 
and monthly income. It also included the medical history with details of the diabetes disease such as duration, complications and causes of it, Frequency of follow-up, had previous hospitalization for DM and Body mass index. The 2nd part consisted of 31 multiple choice and open questions to assess patients' knowledge regarding definition of diabetes, causes, signs and symptoms, complications, such as hypoglycemia, hyperglycemia, diabetic ketoacidosis, and diabetic foot and laboratory investigation and different management strategies as diet, exercises, self-injection, hygiene. The correct and incorrect responses were given " 1 " "0" points respectively. The total scores were calculated by simple summation, and then converted into percentages of total. $\mathrm{Pa}$ tient's knowledge was arbitrarily considered satisfactory at a cutoff point $50 \%$ or more assuming that acquiring of one-half of the information provided would be the minimal level that can positively affect patients' self-efficacy.

The 2nd tool was the self-efficacy scale based on the Diabetes Self-Efficacy Scale of Stanford Patient Education Research Centre ${ }^{[27]}$ adapted by the researchers little modification was done to validated for the culture of Egyptian patient. The scale has 32 items covering 10 areas of self-efficacy: eating, exercises, getting information about DM, getting support from others, routine home activities, recreation and social activities, communicating with doctor, management of DM, management of symptoms, and controlling emotions. The items are scored on a 10-point continuous scale ranging from "1" (Not sure at all) to "10" (Completely sure), so that a greater score indicates more self-efficacy. The total scores were calculated by simple summation, and then converted into percentages of total. For categorical analysis, patient's self-efficacy was arbitrarily considered high if the percent score was $\geq 60 \%$.

The 3rd tool assessed patients' self-reported self-management behaviors concerning self-care practices based on Schmitt et al. ${ }^{[28]}$ and adapted by researchers consisted of eleven parts with 91 items. It included 17 items to assess diet regimen and weight control practices, 3 for exercise, 7 for treatment, 3 for laboratory tests, 12 for insulin injection, 10 for urine testing, 7 for blood glucose testing, 7 for eye care, 5 for personal hygiene, 17 for foot, nail, and wound care, and 3 for follow-up. The items reported "done" and "not-done" were given " 1 " and " 0 " points respectively. The total scores were calculated by simple summation, and then converted into percentages of total. Patient's self-management practices were arbitrarily considered adequate at a cutoff point $60 \%$ or higher.

The data collection tools were face and content-validated through a panel of five experts in medical-surgical nursing.
The tools were then pilot-tested on 5 patients from the study setting to test its understandability and applicability, and to determine the time needed for its filling. This ranged between 30 and 45 minutes according to patient's condition and level of understanding. Based on the pilot results, the researchers modified some of the questions and finalized the tool. The reliability of the self-efficacy scale was also tested in the study through measuring its alpha Cronbach coefficient. This was 0.972 , indicating high level of reliability.

\subsection{Administrative and ethical considerations}

Necessary approvals to conduct the study were secured using official channels. The research and ethics committee at the Faculty of Nursing, Zagazig University approved the protocol. At the initial encounter with each patient, the researchers explained the aim and process of the work and its benefits to obtain an informed oral consent. Each patient was informed about the rights to refuse or withdraw at any time, and about the confidentiality and anonymity of any obtained information. No harm could be anticipated from any maneuver in the implementation of the study; on the contrary, the intervention had potential beneficial effects on participants.

\subsection{Fieldwork}

The study was implemented from January 2013 to June 2014 where the researchers were available two days weekly.

Assessment phase: The researchers started to recruit the sample according to eligibility criteria. Those who gave their consent were interviewed individually using the data collection form. The information obtained served as baseline data or pretest, and guided the researchers in the preparation of the health educational intervention guidelines.

Planning phase: Using the assessment data and related literature, the researchers developed an educational guidelines to train patients and improve their knowledge about T2DM, and self-management behaviors, and related self-efficacy. The health educational intervention guidelines included a theoretical and a practical part. The researchers prepared an illustrated guideline booklet in simple Arabic language to help patients assimilate and refresh the information provided. To achieve aim of the study; knowledge covered the meaning of DM, its signs and symptoms, complications, causes of hypo or hyperglycemia, or ketone in urine, diet, exercises and drug therapy Elements of self-management practice related to lifestyle changes that are: 1) dealing with the symptoms of diabetes including physical and psychological problems; 2) strength and endurance exercises; 3 ) proper diet and weight control; 4) medication administration and self-injection; 5) hygienic care for (teeth, eye, foot, nails and wound); 6) blood glucose test; 7) cooperating with caregivers and 8) impor- 
tance of follow up. Participants are instructed to develop weekly action plans, and interchange experiences to help each other in this.

Implementation phase: The researchers met with the patients individually, and administered the health educational intervention guidelines in twelve 30-45 minutes sessions. One patient's family member attended the sessions to help him/her follow the health educational guidelines at home. The first three sessions were theoretical and covered the meaning of DM, its signs and symptoms, complications, causes of hypo or hyperglycemia, laboratory tests, treatment, as well as eye, nail, foot, and wound care. This was followed by nine practical sessions with applied hands-on training in self-care practices such as dietary regiment and weight control, exercise and daily life activities, treatment, insulin injection, urine and blood glucose testing, personal hygiene, and eye, wound, foot and nail care. During the practical sessions, each patient was assessed whether he/she follows the prescribed guidelines or not. The first session was for orientation about the intervention. The researchers used simple language to suit the level of patients, with motivation and reinforcement to enhance learning. A copy of the guidelines was offered for each patient to use it as future reference.

Table 1. Socio-demographic of patients in the study sample $(\mathrm{n}=50)$

\begin{tabular}{lll}
\hline & Frequency & Percent (\%) \\
\hline Age & 36 & 72.0 \\
$<60$ & 14 & 28.0 \\
$60+$ & $37.0-75.0$ & \\
Range & $54.5 \pm 7.9$ & \\
Mean \pm SD & 55.00 & \\
Median & & \\
Gender & 16 & 32.0 \\
Male & 34 & 68.0 \\
Female & & \\
Marital status & 38 & 76.0 \\
Married & 12 & 24.0 \\
Widow & & \\
Education & 27 & 54.0 \\
Read/write & 10 & 20.0 \\
Basic & 7 & 14.0 \\
Intermediate & 6 & 12.0 \\
University & 18 & \\
Job status & 32 & 28.0 \\
Not working & 36 & \\
Working & 14 & \\
Residence & & \\
Urban & & \\
Rural & & \\
\hline
\end{tabular}

Evaluation phase: Each patient in the study was evaluated three times using the same data collection tools. This was done upon recruitment (pretest), immediately after the end of the health educational intervention guidelines (posttest), and six months after the end of the guidelines (follow-up).

Table 2. Medical and family history of patients in the study sample $(n=50)$

\begin{tabular}{|c|c|c|}
\hline & Frequency & Percent (\%) \\
\hline \multicolumn{3}{|l|}{ Duration of DM (years) } \\
\hline$<5$ & 19 & 38.0 \\
\hline $5-10$ & 9 & 18.0 \\
\hline$>10$ & 22 & 44.0 \\
\hline Has family history of DM & 46 & 92.0 \\
\hline Family history first degree & 4 & 8.0 \\
\hline Have DM complications & 49 & 98.0 \\
\hline \multicolumn{3}{|l|}{ Complications } \\
\hline Hypertension & 30 & 61.2 \\
\hline Eye problems & 21 & 42.9 \\
\hline Hepatic problems & 19 & 38.8 \\
\hline Neurological problems & 16 & 32.7 \\
\hline Slow wound healing & 5 & 10.2 \\
\hline Cardiac problems & 2 & 4.1 \\
\hline Renal problems & 1 & 2.0 \\
\hline Recurrent infections & 1 & 2.0 \\
\hline \multicolumn{3}{|l|}{ Treatment } \\
\hline Oral & 20 & 40.0 \\
\hline Insulin & 16 & 32.0 \\
\hline Both & 14 & 28.0 \\
\hline \multicolumn{3}{|l|}{ Frequency of follow-up } \\
\hline Weekly & 2 & 4.0 \\
\hline Monthly & 36 & 72.0 \\
\hline More than one month & 12 & 24.0 \\
\hline Had hypoglycemic attacks & 50 & 100.0 \\
\hline \multicolumn{3}{|l|}{ Causes } \\
\hline Delayed meal & 40 & 80.0 \\
\hline Excess effort & 20 & 40.0 \\
\hline Excess medications & 9 & 18.0 \\
\hline No cause & 12 & 24.0 \\
\hline Had hyperglycemic attacks & 50 & 100.0 \\
\hline \multicolumn{3}{|l|}{ Causes } \\
\hline Neglect of treatment & 35 & 70.0 \\
\hline Fatty meal & 32 & 64.0 \\
\hline Excess candies & 22 & 44.0 \\
\hline Stress & 19 & 38.0 \\
\hline No cause & 9 & 18.0 \\
\hline $\begin{array}{l}\text { Had previous hospitalization for } \\
\text { DM }\end{array}$ & 2 & 4.0 \\
\hline \multicolumn{3}{|l|}{ Body mass index (BMI) } \\
\hline Normal $(<25)$ & 6 & 12.0 \\
\hline Overweight (25-30) & 15 & 30.0 \\
\hline Obese $(>30)$ & 29 & 58.0 \\
\hline
\end{tabular}




\subsection{Statistical analysis}

Data management was done on SPSS 20.0 statistical software package. Qualitative categorical variables such as the dichotomized results of knowledge, self-efficacy, and selfmanagement, were compared using chi-square test or Fisher exact test as appropriate. Spearman rank correlation was used for assessing the inter-relationships among quantitative variables such as age, duration of disease, and various scores and ranked ones such as the level of education. Multiple linear regression analysis was used to recognize the predictors of knowledge, self-efficacy, and self-management practice scores. Statistical significance was set at $p<.05$.

\section{RESULTS}

Table 1 demonstrates that $68.0 \%$ of the patients were females, and their age ranged between 37 and 75 years. More than half of the patients had no formal education but could read/write $(54.0 \%)$, were unemployed $(72.0 \%)$, and from rural areas $(64.0 \%)$.

Regarding patients' medical and family history, Table 2 illustrates that the duration of DM was mostly ten years or more $(44.0 \%)$, and almost all of them $(92.0 \%)$ had positive family history. All but one patient (98.0\%) had DM complications, mostly hypertension (61.2\%), eye (42.9\%), and neurological $(32.7 \%)$ problems. All patients gave a history of hypoglycemia and hyperglycemia, caused mainly by delayed meal $(80.0 \%)$ and neglect of treatment $(70.0 \%)$ respectively. Two-fifth of the patients $(40.0 \%)$ were on oral medication whereas $28.0 \%$ were on both oral and insulin treatment. The majority $(72.0 \%)$ had monthly follow-up, and were overweight/obese $(88.0 \%)$.

As illustrated in Table 3, patients' knowledge about DM was generally low at the pre-guidelines phase particularly for laboratory tests $(0.0 \%)$, treatment $(2.0 \%)$, foot and wound care $(2.0 \%)$, and hyperglycemia $(4.0 \%)$. The posttest showed significant improvements in all aspects of patients' knowledge about DM, reaching $100.0 \%$ satisfactory knowledge in almost all aspects. This persisted at the follow-up test, with minimal non-significant declines in some areas. In total, more than three quarters $(78.0 \%)$ of the patients had unsatisfactory knowledge at the pretest, compared to none $(0.0 \%)$ at the post and follow-up tests $(p<.001)$.

Table 3. Change in patients' knowledge throughout intervention phases

\begin{tabular}{|c|c|c|c|c|c|c|c|c|}
\hline \multirow{3}{*}{$\begin{array}{l}\text { Satisfactory } \\
\text { Knowledge } \\
(50 \%+) \text { of }\end{array}$} & \multicolumn{6}{|c|}{ Time } & \multirow{3}{*}{$\begin{array}{l}\chi^{2} \text { (p-value) } \\
\text { Pre-post }\end{array}$} & \multirow{3}{*}{$\begin{array}{l}\chi^{2}(p-v a l u e) \\
\text { Pre-FU }\end{array}$} \\
\hline & \multicolumn{2}{|c|}{ Pre $(n=50)$} & \multicolumn{2}{|c|}{ Post $(n=50)$} & \multicolumn{2}{|c|}{ FU $(n=50)$} & & \\
\hline & No. & $\%$ & No. & $\%$ & No. & $\%$ & & \\
\hline DM definition and causes & 19 & 38.0 & 49 & 98.0 & 50 & 100.0 & $41.36\left(<.001^{*}\right)$ & $44.93\left(<.001^{*}\right)$ \\
\hline Symptoms/signs & 15 & 30.0 & 50 & 100.0 & 50 & 100.0 & $53.85\left(<.001^{*}\right)$ & $53.85(<.001 *)$ \\
\hline Complications & 42 & 84.0 & 50 & 100.0 & 50 & 100.0 & Fisher(.006*) & Fisher(.006) \\
\hline Hypoglycemia & 44 & 88.0 & 50 & 100.0 & 50 & 100.0 & Fisher $\left(.03^{*}\right)$ & Fisher(.03*) \\
\hline Laboratory tests & 0 & 0.0 & 50 & 100.0 & 37 & 74.0 & $100.00\left(<.001^{*}\right)$ & $58.73\left(<.001^{*}\right)$ \\
\hline Acetone & 5 & 10.0 & 32 & 64.0 & 32 & 64.0 & $31.27\left(<.001^{*}\right)$ & $31.27\left(<.001^{*}\right)$ \\
\hline Treatment & 1 & 2.0 & 49 & 98.0 & 47 & 94.0 & $92.16\left(<.001^{*}\right)$ & $84.78\left(<.001^{*}\right)$ \\
\hline Exercise & 29 & 58.0 & 50 & 100.0 & 49 & 98.0 & $26.58\left(<.001^{*}\right)$ & $23.31\left(<.001^{*}\right)$ \\
\hline Foot/wound care & 1 & 2.0 & 50 & 100.0 & 48 & 96.0 & $96.08\left(<.001^{*}\right)$ & $88.40\left(<.001^{*}\right)$ \\
\hline \multicolumn{9}{|l|}{ Total } \\
\hline Unsatisfactory & 39 & 78.0 & 0 & 0.0 & 0 & 0.0 & $63.93\left(<.001^{*}\right)$ & $63.93\left(<.001^{*}\right)$ \\
\hline
\end{tabular}

(*) Statistically significant at $p<.05$

Concerning self-efficacy, Table 4 shows very low levels in all its aspects at the pretest. Thus, none of the patients had high self-efficacy regarding recreation and social activities, management of DM, and control of emotions. At the posttest, revealed statistically significant improvements in all aspects of self-efficacy $(p \leq .001)$. The improvement was highest regarding the management of symptoms $(96.0 \%)$ and eating $(80.0 \%)$. The follow-up phase demonstrated some declines but the levels remained significantly higher compared with the pretest in most areas. In total, none $(0.0 \%)$ of the patients had high self-efficacy at the pretest, compared to $56.0 \%$ at the posttest, and $40.0 \%$ at the follow-up test $(p<.001)$.

Table 5 indicates that patients' self-management reported practices were mostly inadequate in all activities at the pretest. The only exception was related to treatment, which was adequate in $98.0 \%$ of the patients. The posttest demonstrated significant ameliorations in most self-management practices. The only exceptions were regarding treatment, which remained as high as in the pretest level, and exercise, lab tests, and follow-up, which remained low as in the pretest. 
The same pattern continued throughout the follow-up, with no changes in these four areas. Moreover, the foot care practices demonstrated marked decrease, but still remained significantly higher compared to pretest $(p=.03)$. In total, only $10.0 \%$ of the patients had adequate self-management reported practices at the pretest, compared to $96.0 \%$ at the posttest, and $60.0 \%$ at the follow-up test $(p<.001)$.

Table 4. Self-efficacy among patients throughout intervention phases

\begin{tabular}{|c|c|c|c|c|c|c|c|c|}
\hline \multirow{3}{*}{$\begin{array}{l}\text { High }(60 \%+) \\
\text { Self-Efficacy }\end{array}$} & \multicolumn{6}{|c|}{ Time } & \multirow{3}{*}{$\begin{array}{l}\chi^{2}(p \text {-value }) \\
\text { Pre-post }\end{array}$} & \multirow{3}{*}{$\begin{array}{l}\chi^{2}(p \text {-value }) \\
\text { Pre-FU }\end{array}$} \\
\hline & \multicolumn{2}{|c|}{ Pre $(n=50)$} & \multicolumn{2}{|c|}{ Post $(n=50)$} & \multicolumn{2}{|c|}{ FU $(n=50)$} & & \\
\hline & No. & $\%$ & No. & $\%$ & No. & $\%$ & & \\
\hline Eating & 4 & 8.0 & 40 & 80.0 & 15 & 30.0 & $52.60(<.001 *)$ & $7.86\left(.005^{*}\right)$ \\
\hline Exercise & 1 & 2.0 & 21 & 42.0 & 11 & 22.0 & $23.31\left(<.001^{*}\right)$ & $9.47\left(.002^{*}\right)$ \\
\hline Get information about DM & 3 & 6.0 & 31 & 62.0 & 6 & 12.0 & $34.94\left(<.001^{*}\right)$ & Fisher(.49) \\
\hline Get support from others & 16 & 32.0 & 32 & 64.0 & 7 & 14.0 & $10.26\left(.001^{*}\right)$ & $4.57\left(.03^{*}\right)$ \\
\hline Routine home activities & 4 & 8.0 & 23 & 46.0 & 7 & 14.0 & $18.32\left(<.001^{*}\right)$ & $0.92(.34)$ \\
\hline Recreation and social activities & 0 & 0.0 & 15 & 30.0 & 5 & 10.0 & $17.65\left(<.001^{*}\right)$ & Fisher(.06) \\
\hline Communicate with doctor & 2 & 4.0 & 23 & 46.0 & 9 & 18.0 & $23.52\left(<.001^{*}\right)$ & $5.01\left(.03^{*}\right)$ \\
\hline Management of DM & 0 & 0.0 & 18 & 36.0 & 5 & 10.0 & $21.95\left(<.001^{*}\right)$ & Fisher(.06) \\
\hline Management of symptoms & 3 & 6.0 & 48 & 96.0 & 48 & 96.0 & $81.03\left(<.001^{*}\right)$ & $81.03(<.001 *)$ \\
\hline Control emotions & 0 & 0.0 & 20 & 40.0 & 20 & 40.0 & $25.00\left(<.001^{*}\right)$ & $25.00(<.001 *)$ \\
\hline \multicolumn{9}{|l|}{ Total self-efficacy } \\
\hline High & 0 & 0.0 & 28 & 56.0 & 20 & 40.0 & & \\
\hline Low & 50 & 100.0 & 22 & 44.0 & 30 & 60.0 & $38.89(<.001 *)$ & $25.00\left(<.001^{*}\right)$ \\
\hline
\end{tabular}

$(*)$ Statistically significant at $p<.05$

Table 5. Total self-management practices reported by patients throughout intervention phases

\begin{tabular}{|c|c|c|c|c|c|c|c|c|}
\hline \multirow{3}{*}{$\begin{array}{l}\text { Adequate } \\
\text { self-management } \\
\text { practice }(60 \%+) \text { of }\end{array}$} & \multicolumn{6}{|c|}{ Time } & \multirow{3}{*}{$\begin{array}{l}\chi^{2} \text { (p-value) } \\
\text { Pre-post }\end{array}$} & \multirow{3}{*}{$\begin{array}{l}\chi^{2}(p \text {-value }) \\
\text { Pre-FU }\end{array}$} \\
\hline & \multicolumn{2}{|c|}{ Pre $(n=50)$} & \multicolumn{2}{|c|}{ Post $(n=50)$} & \multicolumn{2}{|c|}{ FU $(n=50)$} & & \\
\hline & No. & $\%$ & No. & $\%$ & No. & $\%$ & & \\
\hline Diet & 1 & 2.0 & 44 & 88.0 & 41 & 82.0 & $74.71\left(<.001^{*}\right)$ & $65.68\left(<.001^{*}\right)$ \\
\hline Treatment & 49 & 98.0 & 49 & 98.0 & 49 & 98.0 & Fisher(1.00) & Fisher(1.00) \\
\hline Insulin injection & 9 & 29.0 & 31 & 100.0 & 32 & 100.0 & $34.10(<.001 *)$ & $34.90(<.001 *)$ \\
\hline Exercise & 5 & 10.0 & 5 & 10.0 & 5 & 10.0 & $0.00(1.00)$ & $0.00(1.00)$ \\
\hline Lab tests & 10 & 20.0 & 10 & 20.0 & 9 & 18.0 & $0.00(1.00)$ & $0.06(.80)$ \\
\hline Urine test & 6 & 12.2 & 47 & 95.9 & 46 & 93.9 & $69.07\left(<.001^{*}\right)$ & $65.55(<.001 *)$ \\
\hline Blood tests & 9 & 18.0 & 50 & 100.0 & 50 & 100.0 & $69.49\left(<.001^{*}\right)$ & $69.49\left(<.001^{*}\right)$ \\
\hline Personal hygiene & 6 & 12.0 & 50 & 100.0 & 29 & 58.0 & $78.57\left(<.001^{*}\right)$ & $23.25\left(<.001^{*}\right)$ \\
\hline Foot care & 4 & 8.0 & 49 & 98.0 & 12 & 24.0 & $81.29\left(<.001^{*}\right)$ & $4.76\left(.03^{*}\right)$ \\
\hline Follow-up & 18 & 36.0 & 18 & 36.0 & 19 & 38.0 & $0.00(1.00)$ & $0.04(.84)$ \\
\hline Eye care & 4 & 8.0 & 49 & 98.0 & 49 & 98.0 & $81.29(<.001 *)$ & $81.29(<.001 *)$ \\
\hline \multicolumn{9}{|l|}{ Total } \\
\hline Adequate & 5 & 10.0 & 48 & 96.0 & 30 & 60.0 & & \\
\hline Inadequate & 45 & 90.0 & 2 & 4.0 & 20 & 40.0 & $74.23\left(<.001^{*}\right)$ & $27.47\left(<.001^{*}\right)$ \\
\hline
\end{tabular}

(*) Statistically significant at $p<.05$

Concerning the correlations among patients' knowledge, selfmanagement practice, and self-efficacy scores before the intervention, Table 6 indicates statistically significant weak to moderate positive correlations among the three scores. The table also shows that patients' self-efficacy correlated positively with education and negatively with the duration of DM, the number of complaints, and the number of hyperglycemic attacks. Meanwhile, the knowledge score correlated positively with the number of hypoglycemic attacks, whereas the practice correlated negatively with the number of hyperglycemic attacks.

In multivariate analysis (see Table 7), the statistically significant independent positive predictors of patients' knowledge score throughout the study phases were the intervention and the dual oral/insulin therapy. As indicated by the standardized coefficient, the intervention was the most influential factor. It is evident that $23 \%$ of the variance in the knowledge score can be attributed to the factors in the model. 
Table 6. Correlation between patients' knowledge, practice, and self-efficacy scores and their characteristics before the intervention

\begin{tabular}{llll}
\hline \multicolumn{3}{c}{$\begin{array}{l}\text { Spearman's rank correlation } \\
\text { coefficient }\end{array}$} \\
\cline { 2 - 4 } & Knowledge & Self-efficacy & Practice \\
\hline Knowledge & $.290^{*}$ & & \\
Self-efficacy & $.443^{* *}$ & $.425^{* *}$ & \\
Practice & -0.13 & -0.16 & -0.19 \\
Age & 0.03 & $.38^{* *}$ & 0.19 \\
Education & -0.08 & -0.02 & -0.07 \\
BMI & 0.00 & $-.29^{*}$ & -0.15 \\
DM duration & 0.02 & $-.36^{* *}$ & -0.11 \\
No. of complaints & $.36 *$ & -0.02 & -0.18 \\
No. of hypoglycemic attacks & 0.08 & $-.31^{*}$ & $-.41^{* *}$ \\
No. of hyperglycemic attacks & 0. & & \\
\hline
\end{tabular}

$(*)$ Statistically significant at $p<.05,(* *)$ Statistically significant at $p<.01$
The model for the self-efficacy score indicates that the significant positive predictor of this score throughout the study phases was the intervention while the duration of DM was a negative predictor. As indicated by the standardized coefficient, the intervention was the most influential factor. As $r$-square indicates, $75 \%$ of the variance of self-efficacy score is attributed to the factors in the model.

As for self-management practice score, the statistically significant independent positive predictors were patient's level of education, previous hospitalization, as well as the knowledge and self-efficacy scores. Meanwhile, the rural residence and the dual therapy were negative predictors. The model shows that the knowledge score was the most influential factor followed by the self-efficacy score. The model shows that $87 \%$ of the self-management practice score variance is explained by the factors in the model.

Table 7. Best fitting multiple linear regression model for the knowledge score

\begin{tabular}{|c|c|c|c|c|c|c|c|}
\hline & \multicolumn{2}{|c|}{$\begin{array}{l}\text { Unstandardized } \\
\text { Coefficients }\end{array}$} & \multirow{2}{*}{$\begin{array}{l}\text { Standardized } \\
\text { Coefficients }\end{array}$} & \multirow[t]{2}{*}{$t$-test } & \multirow[t]{2}{*}{$p$-value } & \multicolumn{2}{|c|}{$\begin{array}{l}\text { 95\% Confidence } \\
\text { Interval for B }\end{array}$} \\
\hline & B & Std. Error & & & & Lower & Upper \\
\hline \multicolumn{8}{|l|}{ Knowledge score } \\
\hline Constant & 40.51 & 6.00 & & 6.75 & $<.001$ & 28.66 & 52.37 \\
\hline Oral + insulin therapy & 5.70 & 2.41 & 0.17 & 2.37 & .019 & 0.95 & 10.46 \\
\hline Intervention & 13.38 & 2.07 & 0.46 & 6.45 & $<.001$ & 9.28 & 17.48 \\
\hline \multicolumn{8}{|c|}{$\begin{array}{l}r \text {-square }=0.23 \text {; Model ANOVA: } F=23.81, p<.001 \\
\text { Variables entered and excluded: age, sex, education, marital status, job status, residence, BMI, duration of DM, family history, treatment type, FU, } \\
\text { hospitalization }\end{array}$} \\
\hline \multicolumn{8}{|c|}{ Self-efficacy score } \\
\hline Constant & -15.18 & 6.63 & & -2.29 & .024 & -28.34 & -2.03 \\
\hline Duration of DM & -4.78 & 1.56 & -0.16 & -3.06 & .003 & -7.88 & -1.68 \\
\hline Intervention & 49.22 & 2.93 & 0.85 & 16.83 & $<.001$ & 43.42 & 55.03 \\
\hline \multicolumn{8}{|c|}{$\begin{array}{l}r \text {-square }=0.75 ; \text { Model ANOVA: } F=146.24, p<.001 \\
\text { Variables entered and excluded: age, sex, education, marital status, job status, BMI, family history, treatment type, FU, hospitalization, knowledge } \\
\text { score }\end{array}$} \\
\hline \multicolumn{8}{|c|}{ Self-management practice score } \\
\hline Constant & 38.65 & 3.07 & & 12.58 & $<.001$ & 32.55 & 44.75 \\
\hline Rural residence & -4.50 & 1.41 & -0.12 & -3.19 & .002 & -7.30 & -1.70 \\
\hline Education & 1.51 & 0.61 & 0.09 & 2.48 & .015 & 0.30 & 2.72 \\
\hline Hospitalization & 15.53 & 3.50 & 0.17 & 4.44 & $<.001$ & 8.58 & 22.48 \\
\hline Oral + insulin therapy & -4.48 & 0.83 & -0.21 & -5.42 & $<.001$ & -6.12 & -2.84 \\
\hline Knowledge score & 0.35 & 0.04 & 0.59 & 9.31 & $<.001$ & 0.28 & 0.43 \\
\hline Self-efficacy & 0.21 & 0.04 & 0.34 & 5.47 & $<.001$ & 0.13 & 0.28 \\
\hline
\end{tabular}

\section{Discussion}

This study assessed the effect of health educational intervention guidelines on T2DM patients' knowledge, selfmanagement practices and self-efficacy. The findings generally point to significant improvements in all these three parameters. This would lead to rejection of the null hypotheses regarding the effectiveness of the health education guide- lines. The sample involved 50 adult T2DM patients who represented the population of patients with T2DM in terms of age and gender. The age ranged between 37 and 75 years, with median 55 years, which is the age with highest prevalence of T2DM as reported by Rydén (2014) ${ }^{[29]}$ and Zam et al. (2015). ${ }^{[30]}$ The representativeness was also evident from the higher percentage of females, which is an often-cited find- 
ing in diabetes research in the United Kingdom (Diabetes in the UK, 2012; ${ }^{[31]}$ Kousoulis et al., 2014 ${ }^{[32]}$ ), and well as in Egypt (Taha, 2011 ${ }^{[33]}$ ).

According to the present study, more than three quarters of the patients' total knowledge was unsatisfactory at the pretest. The deficiency was most evident concerning laboratory tests, treatment, and foot care. The finding is alarming since the lack of information has negative repercussions on patient's outcomes. In fact, the study revealed positive correlations between patients' knowledge scores and their self-management practices. Moreover, the multivariate analysis revealed that this score was the most influential factor in improving patients' self-management scores. The finding indicates the crucial need for patient health educational guidelines. In congruence with this, Kolb et al. (2014), ${ }^{[34]}$ in a study in the United States, reported low level of knowledge about diabetes among patients, and discussed the importance of sound patient information on success of management. Furthermore, Liebhauser et al. (2014) ${ }^{[35]}$ in Austria, mentioned that diabetic patients' knowledge about specific dietary ingredients helps in improving their dietary habits.

At the post-intervention phase of the current study, there were significant ameliorations in patient's knowledge, and this persisted during the follow-up. This improvement could be attributed to the guidelines content, which was based on patients' needs, as well as its process where adult learning methods with active participation was used. The effect of the health educational intervention guidelines was confirmed by the regression analysis, which determined the intervention as a main independent predictor of the improvement of knowledge. The finding is in agreement with Abdo and Mohamed $(2010)^{[36]}$ in Egypt and Borhani et al. (2015) $)^{[37]}$ in Iran, who reported a similar success of an educational intervention for T2DM patients. Also in line with the current study results, Lewis et al. (2015) ${ }^{[38]}$ in a study in the United States revealed a retention of the post-intervention improvement in patients' knowledge at follow-up testing.

The present study was also aimed at improving T2DM patients' self-efficacy. The findings revealed markedly low levels of self-efficacy at the pretest. This deficiency could be attributed to the low education grades, in addition to the lack of knowledge. In fact, the study showed significant and positive correlations between patients' self-efficacy score and their educational level and knowledge score. In congruence with this current study finding, a study in the Netherlands demonstrated low levels of self-efficacy among T2DM patients. $^{[39]}$

The implementation of the present study health educational intervention guidelines led to significant improvements in patients' self-efficacy. The role of the intervention in this improvement was further consolidated through the regression analysis, which identified it as a main positive predictor of the self-efficacy score. The finding is in agreement with the findings of similar interventions in the United States ${ }^{[40]}$ and in China ${ }^{[41]}$ The positive effect of the current study guidelines can be attributed to its process, where the researchers stressed patient's role in management of his/her illness. An additional important factor was the presence of a family member during the sessions, which was intended to strengthen this role. In agreement with this, a study in Thailand reported that family involvement is essential in improving the self-efficacy of T2DM patients, and this may help prevent complications. ${ }^{[42]}$

The ultimate goal of this current study was to improve the T2DM patients' self-management behaviors, which would be reflected in better self-care practices. The study revealed obviously inadequate self-management behaviors and self-care practices before the implementation of the guidelines. This was quite expected given the mostly low educational level of the patients. Similarly low levels of self-management with regard to healthy diet, exercise, checking blood glucose, foot care, problem solving, and risk-reduction were reported in a study in Oman. ${ }^{[43]}$ The consequences of such deficient behaviors and practices were evident in the finding that all patients had T2DM complications. Moreover, the results indicated a significant negative correlation between the scores of selfmanagement behaviors/practices and the number of hyperglycemic attacks. In line with this, the Society of Behavioral Medicine's position statement: "expand United States health plan coverage for diabetes self-management education and support" emphasized the role of self-management behaviors in mitigating the complications of T2DM. ${ }^{[4]}$

At the post-intervention phase of the present study, significant improvements were shown in patients' self-management behaviors/practices, and this persisted in the follow-up although with some decline. A similar success of a nursing intervention in enhancing T2DM patients' self-management was reported in a study in Korea, which concluded that promoting personal motivation and self-efficacy could result in better health outcomes. ${ }^{[45]}$ Meanwhile, the multivariate analysis in the present study showed that the educational intervention was not a direct predictor of the patients' selfmanagement/practice scores, but it acted through improving their knowledge and self-efficacy scores. This emphasizes the importance of good patient information about the illness in addition to increased patients' participation, selfconfidence in making choices and decisions regarding the management of their disease, and of intensifying patients' belief in future change. In congruence with this, studies have demonstrated the role of self-efficacy in adherence to 
self-care practices and better glycemic control. ${ }^{[7,46]}$

Other factors that influenced patients' knowledge, selfefficacy, and self-management behaviors/practices involved the disease duration and type of treatment, the level of education, and the residence. The duration of illness had a negative effect on patients' self-efficacy, which could be attributed to the boredom with the long-term lifetime management of the disease. As for the mode of treatment, those patients on oral/insulin therapy benefited more from the knowledge part of the guidelines, but less from self-management. This might be due to that patients may have good practice of medication intake, but with no background knowledge. Thus, the guidelines had a more evident effect on their knowledge. The positive effects of higher education and urban residence are quite expected and are in agreement with previous studies. ${ }^{[47-49]}$

\section{CONCLUSION AND RECOMMENDATIONS}

The study findings demonstrate the effectiveness of health education guidelines in improving T2DM patients' selfmanagement behaviors and self-care practices through provision of sound information about the disease and fostering their self-efficacy. The slight decline at the follow-up phase indicates the need for periodic booster doses of the intervention. Therefore, the study recommends generalization of such educational guidelines in all health care settings providing services to T2DM patients. Such guidelines should particularly address the patients with low educational attainments, long history of T2DM, and those residing in rural areas. Further studies are proposed to evaluate the long-term effect of such interventions.

\section{CONFLICTS OF INTEREST DisClosure}

The authors declare that there is no conflict of interest.

\section{REFERENCES}

[1] World Health Organization. Diabetes. 2013. Available from: http://www . who.int/mediacentre/factsheets/fs312/en/ index.html (accessed on 8 April 2013).

[2] Adewale SO, Adekanmbi DB, Olanrewaju PO. Effect of Glucose intake on the Stability of a Dynamical Model used for the study of diabetes mellitus. Research Journal of Pharmaceutical, Biological and Chemical Sciences. April-June 2013; 4(2): 60.

[3] Oza-Frank R, Stephenson R, Narayan KM. Diabetes prevalence by length of residence among US immigrants. J. Immigr. Minor. Health. 2011; 13: 1-8. PMid:19688263. http://dx.doi.org/10.1007/s 10903-009-9283-2

[4] Rajpathak SN, Wylie-Rosett J. High prevalence of diabetes and impaired fasting glucose among Chinese immigrants in New York City. J. Immigr. Minor. Health. 2011; 13: 181-183. PMid:20533090. http://dx.doi.org/10.1007/s10903-010-9356-2

[5] Xu Y, Pan W, Liu H. The role of acculturation in diabetes selfmanagement among Chinese Americans with type 2 diabetes. Diabetes Res. Clin. Pract. 2011; 93: 363-370. PMid:21636157. http: //dx.doi.org/10.1016/j.diabres.2011.05.010

[6] Grey M, Knafl K, McCorkle R. A framework for the study of selfand family management of chronic conditions. Nurs. Outlook. 2006; 54: 278-286. PMid:17027605. http://dx.doi.org/10.1016/j .outlook. 2006.06.004

[7] Haas L, Maryniuk M, Beck J, et al. National standards for diabetes self-management education and support. Diabetes Care. 2013; 36: S100-S108.

[8] Wang Y, Chuang L, Bateman WB. Focus group study assessing selfmanagement skills of Chinese Americans with type 2 diabetes mellitus. J. Immigr. Minor. Health. 2012; 14: 869-874. PMid:21877209. http://dx.doi.org/10.1007/s10903-011-9514-1

[9] Zeng B, Sun W, Gary RA, et al. Towards a Conceptual Model of Diabetes Self-Management among Chinese Immigrants in the United States. Int. J. Environ. Res. Public Health. 2014; 11: 6727-6742.

[10] Garber JA. Comprehensive Diabetes Management Algorithm, Endocr Pract. Endocrine Practice. 2015 April; 21(4).
[11] Wu SFV, Lee MC, Liang SY, et al. Effectiveness of a self-efficacy program for persons with diabetes: a randomized controlled trial. Nursing \& Health Sciences. 2011; 13: 335-343.

[12] Van der Ven NCW, Weinger K, Yi J, et al. The confidence in diabetes self-care scale. Diabetes Care. 2003; 26: 713e718.

[13] Mishalia M, Omera H, Heymann AD. The importance of measuring self-efficacy in patients with diabetes. Family Practice. 2011; 28: 82-87. PMid:21047940. http://dx.doi.org/10.1093/fampra/ cmq086

[14] Martinez Y, Campbell SM, Hann M, et al. The relationship between quality of care and self-management in patients with type 2 diabetes: a cross-sectional survey in primary care in Mexico. 2014; 22(6): 262-9.

[15] Robert P. FDA Issues Warning for Type 2 Diabetes Drugs SGLT2 inhibitors linked to potentially fatal condition called ketoacidosis, Health Day News, Medline plus. May 18, 2015 (access on 13/6/2015 at 8.30). http://www.nlm.nih.gov/medlineplus/ news/fullstory_152605.html

[16] Rajati F, Sadeghi M, Feizi A, et al. Self-efficacy strategies to improve exercise in patients with heart failure: A systematic review. ARYA Atheroscler. 2014 Nov; 10(6): 319-33.

[17] Dutton GR, Tan F, Provost BC, et al. Relationship between selfefficacy and physical activity among patients with type 2 diabetes. Journal of Behavioral Medicine. 2009; 32: 270-277. PMid:19156510. http://dx.doi.org/10.1007/s10865-009-9200-0

[18] Martin MY, Person SD, Kratt P, et al. Relationship of health behavior theories with self-efficacy among insufficiently active hypertensive African-American women. Patient Educ Couns. 2008; 72 : 137-45. PMid:18395395. http://dx.doi.org/10.1016/j.pec .2008 .02 .012

[19] Chiba Y, Kimbara Y, Kodera R, et al. Risk factors associated with falls in elderly patients with type 2 diabetes. Department of Diabetes, Metabolism, and Endocrinology, Tokyo Metropolitan Geriatric Hospital, 35-2, Sakae-cho, Itabashi-ku, Tokyo, 173-0015, Japan. Journal of Diabetes and Its Complications. 2015; 29(5). 
[20] King DK, Glasgow RE, Toobert DJ, et al. Self-efficacy, problemsolving and social-environmental supports are associated with diabetes self-management behaviors. Diabetes Care. 2010; 33: 751-753. PMid:20150299. http://dx. doi .org/10.2337/dc09-1746

[21] Howells LAL. Self-efficacy and diabetes: why is emotional 'education' important and how can it be achieved? Horm Res. 2002; 57: 6971. PMid:11979027. http://dx.doi .org/10.1159/000053317

[22] Glasgow RE, Anderson RM. In diabetes care, moving from compliance to adherence is not enough. Something entirely different is needed. Diabetes Care. 1999; 22: 2090-2092. PMid:10587854. http://dx.doi.org/10.2337/diacare.22.12.2090

[23] Erol O, Enc N. Hypoglycemia Fear and Self-efficacy of Turkish Patients Receiving Insulin Therapy. Asian Nursing Research. 2011; 5: 222-228. PMid:25030524. http://dx.doi.org/10.1016/j.anr .2011 .12 .001

[24] Mcdonald KJ. Self-Efficacy Case Study, Self-Efficacy and Social Cognitive theory Study. 2013. https://wikispaces.psu.edu/d isplay/PSYCH484/Spring+2013+Self-Efficacy/Case/ Feb. 25, 2013

[25] Bandura A. Self-efficacy: toward a unifying theory of behavioral change. Psychol Rev. 1977; 84: 191-215. http://dx.doi.org/1 $0.1037 / 0033-295 X .84 .2 .191$

[26] Petersen E. Self-efficacy and Social Cognitive Theory. 2013. Available from: https://wikispaces.psu.edu/display/PSYCH48 4/7.+Self-Efficacy+and+Social+Cognitive+Theories

[27] Diabetes Self efficacy Scale, Stanford Patient Education Research Centre. 2004. Available from: http://patienteducation.sta nford.edu/research/sediabetes.html (accessed November 2011).

[28] Schmitt A, Gahr A, Hermanns N, et al. The Diabetes SelfManagement Questionnaire (DSMQ): development and evaluation of an instrument to assess diabetes self-care activities associated with glycaemic control. Health and Quality of Life Outcomes. 2013; 11: 138. Available from: http://www.hqlo.com/content

[29] Rydén L, et al. ESC Guidelines on diabetes, pre-diabetes, and cardiovascular diseases developed in collaboration with the EASD. March 2014. http://dx.doi.org/10.1093/eurheartj/ehu076

[30] Zam K, Kumar AM, Achanta S, et al. A first country-wide review of Diabetes Mellitus care in Bhutan: time to do better. BMC Health Serv Res. 2015 Sep 17; 15(1): 389.

[31] Diabetes in the UK 2012 - Key statistics on diabetes; Diabetes UK, April 2012. Available from: http://patient.info/doctor/di abetes-mellitus.

[32] Kousoulis, et al. Diabetes self-management arrangements in Europe: a realist review to facilitate a project implemented in six countries BMC Health Services Research. 2014; 14: 453. Available from: http://www.biomedcentral .com/1472-6963/14/453

[33] Taha MN, et al. Factors Affecting Compliance of Diabetic Patients toward Therapeutic Management. Medical Journal Cairo University. 2011; 79(1).

[34] Kolb JM, Kitos NR, Ramachandran A, et al. What do primary care prediabetes patients need? A baseline assessment of patients engaging in a technology-enhanced lifestyle intervention. J Bioinform Diabetes. 2014 Feb 2; 1(1): 4.

[35] Liebhauser M, Ofner M, Mittermayer F. Successful Management of Type 2 Diabetes with Lifestyle Intervention: A Case Report. Int J Vitam Nutr Res. 2014; 84(3-4): 133-9. PMid:26098477.
[36] Abdo NM, Mohamed ME. Effectiveness of Health Education Program for Type 2 Diabetes Mellitus Patients Attending Zagazig University Diabetes Clinic, Egypt Community medicine Department Faculty of Medicine, Zagazig University J Egypt Public Health Assoc. 2010; 85(3): 113-130. PMid:21244813.

[37] Borhani M, Rastgarimehr B, Shafieyan Z, et al. Effects of predisposing, reinforcing and enabling factors on self-care behaviors of the patients with diabetes mellitus in the Minoodasht city, Iran. J Diabetes Metab Disord. 2015 Apr 14; 14: 27.

[38] Lewis VR, Benda N, Nassar C, et al. Successful patient diabetes education in the emergency department. Diabetes Educ. 2015 Jun; 41(3): 343-50.

[39] van der Wulp I, de Leeuw JR, Gorter KJ, et al. Effectiveness of peerled self-management coaching for patients recently diagnosed with Type 2 diabetes mellitus in primary care: a randomized controlled trial. Diabet Med. 2012 Oct; 29(10): e390-7.

[40] Wolf MS, Seligman H, Davis TC, et al. Clinic-based versus outsourced implementation of a diabetes health literacy intervention. $\mathrm{J}$ Gen Intern Med. 2014 Jan; 29(1): 59-67.

[41] Ha M, Hu J, Petrini MA, et al. The effects of an educational selfefficacy intervention on osteoporosis prevention and diabetes selfmanagement among adults with type 2 diabetes mellitus. Biol Res Nurs. 2014 Oct; 16(4): 357-67.

[42] Sirikamonsathian B, Sriratanaban J, Hiransuthikul N, et al. Selfefficacy in diabetic care and occurrence of adverse events in an ambulatory setting. Int J Qual Health Care. 2013 Dec; 25(6): 673-81.

[43] Alrahbi H. Diabetes self-management (DSM) in Omani with type-2 diabetes School of Nursing, College of Pharmacy and Nursing, University of Nizwa, Birkat Almooz, Omanm. International Journal of Nursing sconces. 2014: 352-359.

[44] Sharp LK, Fisher EB, Gerber BS. Background and rationale for the Society of Behavioral Medicine's position statement: expand United States health plan coverage for diabetes self-management education and support. Transl Behav Med. 2015 Sep; 5(3): 3546. PMid:26327941. http://dx.doi.org/10.1007/s13142-015 $-0328-\mathrm{x}$

[45] Jung SY, Lee SJ, Kim SH, et al. A predictive model of health outcomes for young people with type 2 diabetes. Asian Nurs Res (Korean Soc Nurs Sci). 2015 Mar; 9(1): 73-80.

[46] Kwan CM, Mullan JT, Chun KM, et al. Social relationships and health among Chinese Americans: Does age make a difference? Clin. Gerontol. 2014; 37: 191-210.

[47] Joshi A, Mehta S, Grover A, et al. Knowledge, attitude, and practices of individuals to prevent and manage metabolic syndrome in an Indian setting. Diabetes Technol Ther. 2013 Aug; 15(8): 644-53.

[48] Cosansu G, Erdogan S. Influence of psychosocial factors on selfcare behaviors and glycemic control in Turkish patients with type 2 diabetes mellitus. J Transcult Nurs. 2014 Jan; 25(1): 519. PMid:24084701. http://dx.doi.org/10.1177/104365961 3504112

[49] Bos-Touwen I, Schuurmans M, Monninkhof EM, et al. Patient and disease characteristics associated with activation for self-management in patients with diabetes, chronic obstructive pulmonary disease, chronic heart failure and chronic renal disease: a cross-sectional survey study. PLoS One. 2015 May 7; 10(5): e0126400. 